* Trabalho apresentado no I Forum de Debates da Facul. dade de Saude Pública da Universidade de Säo Paulo, reali. zado em 24 de dezembro de 1985.

* Do Departamento de Epidemiologia da Faculdade de Saúde Pública da Universidade de Säo Paulo, Av. Dr. Arnaldo, 715, Säo Paulo, SP, CEP 01255, Brasil.

\section{Significado do Estudo de Caso em Epidemiologia*}

\author{
Lygia Busch Iversson**
}

Discute-se a utilização do estudo de caso em epidemiologia, analisando as vantagens e as dificuldades que o método oferece.

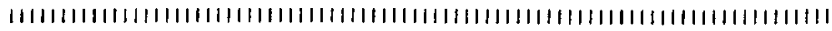

Sendo a epidemiologia uma ciência dirigida ao estudo da distribuição de agravos ou da própria saúde em uma população, o raciocínio epidemiológico se desenvolve pelo estudo comparado de agrupamentos de indivíduos, constituidos segundo variáveis pré-determinadas. Cada um desses agrupamentos, resultantes de uma soma, assume certa individualidade no que se refere à variável considera$\mathrm{da}$, como se todos os elementos componentes fossem idênticos não só à expressão desta variável como quanto ao que conduziu a essa expressão. No entanto, é fato inconteste a singularidade de cada indivíduo em sua biologia, estilo de vida e forma de relacionamento com o meio e outros seres vivos. Nessa singularidade reside mesmo a grandeza e o mistério da vida. Assim, uma ciência que objetiva a identificação das causas que determinaram a ocorrência de determinados agravos na população deveria incorporar à sua metodologia de trabalho, ao lado da análise dos grupos de indivíduos, a análise de caso individual.

Mas será que isto já não é feito? Certamente, de uma forma já institucionalizada, nas situações:

1. Quando da coleta de dados o epidemiologista procura verificar a qualidade da informação, analisando cada ficha de investigação epidemiológica, prontuário hospitalar ou outra forma de registro individual com a finalidade de conferir a informação coletiva e/ou a completar com dados eventualmente ano tados.

2. Quando da identificação da fonte de infecção e dos comunicantes de um caso suspeito ou confirmado de molés. tia de notificação compulsória, existe a preocupação da análise individual do caso, com vistas à profilaxia.

3. Quando do estudo de um caso de doença cuja ocorrência não possa ser explicada pelo que se conhece da sua epidemiologia. A "análise do resíduo" é praticada, em geral, em um conjunto de casos que não apresentavam os requisitos conhecidos para serem atingidos pelo agravo, mas pode ser feita a partir de uma só pessoa. É um procedimento utilizado na formulação de novas hipóteses causa is. Assim se esclareceu, por exemplo, a forma de transmissão por transfusão sanguínea de conhecidas endemias rurais 
como a malária e a tripanossomíase americana.

Excluidas essas situacōes, na epidemiologia clássica o indivíduo cede sua individualidade para o conjunto a que pertence, seja um grupo etário, seja um grupo profissional, ou outro qualquer. A unidade de trabalho não é o indivíduo mas o grupo. Todo ojogo analítico se movimenta em torno de números.

Obviamente, a análise individual nâo tem significado estatístico para comprovar uma hipótese causal, o que não impede que ela seja útil para ajudar a formular esta hipótese ou para refinar a sua comprovação, dentro de uma perspectiva mais qualitativa. $\mathrm{Na}$ condução do raciocínio epidemiológico observa-se que incontáveis vezes a hipótese causal emergiu a partir do estudo invidual de um caso. Certamente foi a observação dos aspectos relacionados ao estilo de vida decorrente da cultura e condição sócio-econômica do observado que norteou a mente para a hipótese. Também após a sua comprovação estatística intuitivamente verifica-se sua procedência em casos individuais que se destacaram na memória.

Historicamente a análise individual com vistas a causalidade dos agravos coletivos vem sendo utilizada na área clínica. A chamada técnica de História de Vida ou Estudo de Caso, é prática usual para o pesquisador social no entendimento dos comportamentos sociais. O método é definido em termos genéricos, como "o estudo in tensivo de um número reduzido de eventos ou de um só. Pode corresponder também a parte ou fase relevante da totalidade de um acontecimento; assim a unidade de estudo pode ser uma pessoa, um grupo, uma comunidade, um efeito, uma decisão, uma instituição, uma organização complexa: caracteriza-se pela análise intensiva, tanto em amplitude quan to em profundidade; sem dúvida, a intensidade da análise é sensível ao número de aspectos do caso em estudo, ou da mostragem utilizada". "Boyd e Harper ${ }^{2}$ discutem se o método é um tipo de pesquisa descritiva ou um mé todo de pesquisa exploratória ou um passo no processo de pesquisa e citam Lundbergen que o considera. tal como as técnicas estatísticas, como um dos estágios no desenvolvimento de um método científico.

Se este procedimento, centrado no estudo de um indivíduo, vem sendo utilizado de modo não-programado por aqueles que habitualmente praticam o raciocínio epidemiológico, por que não incorporá-lo definitivamente de uma forma fundamentada tecnicamente? Em linhas básicas o que se necessi ta está contido em très questões: Quem selecionar para análise individual? Qual o instrumento de abor. dagem? Qual a sistemática para a análise de informação?

O critério para a escolha de indivíduos é, no dizer do pesquisador social com experiência, um dos pontos mais controvertidos na utilização da técnica de Estudo de caso. ${ }^{5}$

A seleção de tipos "representativos" da populaçãoalvo far-se-ia basicamente por dois mecanismos: 
1. Combinação da história de vida com inquérito sociológico onde se utilizaria como instrumento de coleta de dados a técnica de entrevista ou questionário. Fernandes $^{5}$ refere como inconvenientes da entrevista o fato de prolongar o periodo de coleta de dados, refletindo no custo da pesquisa, e não permitir um tratamento estatístico dos fatores significa tivos para a seleção dos indivíduos. A aplicação de formulários, que estabelece um conta to maior do pesquisador com o investigado e permite um tratamen to estatístico daqueles fatores, seria, para aquele autor, a combinação ideal para seleção das pessoas a serem estu da das in dividualmente.

$\mathrm{Na}$ prática epidemiológica freqüentemente a coleta de dados é feita em registros padronizados que não possibilitam, em geral, "janelas" para visualizar se indivíduos selecionados para estudo de caso, tendo em vista fatores considerados significativos, sem que haja oportundidade de um conhecimento pessoal, corresponderão à expectativa do objetivo do estudo. Tal não ocorre quando a informação é gerada a partir de um inquérito epidemiologista. A seleaplicação de um formulário pelo epidemiologista. A sele. ção dos casos será factível, obedecendo aos requisitos de representatividade em relação à população-alvo, no que se refere a uma dada característica julgada relevante (por exemplo, grupo etário, ocupação, local de residência) e por características pessoais do entrevistado (por exemplo, compreensão, espontaneidade no relato de fatos e manifestação de opiniões).

A experiência prática sugere a utilização seqüencial desses mesmos requisitos, ou seja, numa dupla seleção, quando a fonte de dados for num registro. Exemplificando, durante um estudo da epidemia de encefalite por arbovi. rus no litoral sul de São Paulo ${ }^{6}$, selecionaram-se, em uma primeira etapa, os casos notificados em crianças menores de 4 anos de idade, residentes na área urbana de Iguape, um dos municípios mais atingidos pela moléstia, com vistas a informações que elucidassem a hipótese de transmissão domiciliar e urbana dessa arbovirose. Procedeu-se a visita domiciliar para entrevistar os responsáveis das crianças. Esta primeira abordagem permitiu escolher casos para um estudo mais aprofundado em razão de sua represen ta tividade quanto ao fator relevante em estudo - permanência constante da criança na área urbana e no domicílio em de. corrência de hábito de vida. Coletaram-se informaçōes valiosas para a hipótese de estar ocorrendo tam bém transmissão urbana e domiciliar dessa arbovirose à população, os quais orientaram pesquisas ulteriores.

2. Pela utilização da experiência acumulada pelo próprio investigador como membro de um grupo participante de uma subcultura. Nessa condição, $O$ invest jgador atuaria ou como um caso, analisando sua própria experiência ou como seletor de casos a serem estudados. O subjetivismo das observaçōes poderia ser controlado pela experiência e

Cadernos de Saúde Pública, RJ., 3 (1): 16-21, jan/fev, 1987 
rigor do investigador no aproveitamento e na análise dos resultados. ${ }^{5}$

Brandão ${ }^{3}$ sintetiza esta postura ao referir que tudo se resolve com uma boa teoria no princípio, uma objetiva neutralidade no meio e uma rigorosa articulação de ambas as coisas com os dados obtidos, no final.

Obviamente, a escolha dos casos se fará no círculo de pessoas com as quais o investigador, na qualidade de observador-participante, conviveu e com quem estabeleceu laços de simpatia e comunicação fácil. A seleção obedeceria ao acaso e haveria a possibilidade de serem selecionadas as chamadas "personalidades divergentes" 5 com comportamentos e opiniões diferentes do padrão comum. Desde que o investigador identifique essa divergência "a priori". poderá usá-la positivamente para enriquecer suas informações, verificando como essas personalidades in teragem com outros indivíduos da comunidade analisada. Além do mais. a divergéncia pode ser uma característica transitória gerada por uma situação circunstancial de não-integração na sociedade a ser analisada. Exemplificando. no estudo da rede causal de um agravo de saúde as informações de pessoas recém-chegadas ao local ou, embora ali nascidas, recémingressas no grupo social onde está ocorrendo o agravo. permitem a identificação de fatores que passariam desper. cebidos aos integrantes de longa data no grupo. Selltiz e colaboradores ${ }^{9}$ incluem os divergentes e os isolados entre os que merecem ser investigados, geradores de informaçöes sobre os tipos de pressão para o conformismo e as consequências sócio-psicológicas do não-conformismo naquela comunidade ou para evidenciar os fatores de união e a forma pela qual a informação e as atitudes são transmitidas em um grupo.

$\mathrm{Na}$ escolha do instrumento de abordagem é básico que este possibilite um clima de confiança e de tranqüili. dade que permita ao entrevistado relatar com a maior honestidade os acontecimentos e sua opinião sobre eles. Nesse contexto, a narrativa livre orientada por perguntas abertas do investigador parece assegurar o cumprimento das quatro regras propostas por Bowley, citadas por Mann ${ }^{8}$ para a formulação de um roteiro de entrevistas:

a) Pedir as informações necessárias em termos de quantidade e qualıdade.

b) Assegurar-se de que as perguntas podem ser respondidas.

c) Assegurar-se de que as perguntas serão respondidas honestamente.

d) Assegurar-se de que as perguntas serão respondidas e não recusa das.

A clareza, a concisão, a não sugestão das respostas, a sensibilidade em valorizar uma informação no curso de uma resposta são fatores usualmente citados na formulação das questões no curso de uma entrevista ${ }^{14}$. A a titude sinceramente in teressada e solidária do investigador é. para quem já vivenciou a experiência. a chave para que a informação 
flua e permita um espontâneo direcionamento da narrativa em pontos relevantes para o objetivo da investigação.

Em relação à análise dos dados, feita sem os processos estatísticos formais, impõem-se algumas precauções:

1. risco, de interferência das opiniōes preexistentes do investigador;

2. generalização de informações coletadas em casos incomuns;

3. barreiras de comunicação pelo imperfeito entendimen to da linguagem usada pelo entrevistado, já assinaladas por Malinowski em seus trabalhos pioneiros da década de $1910^{7}$, in terferin do na in terpretação dos dados.

Essas dificuldades desaparecem na medida que 0 investigador procurar se identificar, dentro do possivel, com o investigado, aprendendo a pensar através de sua lógica. É evidente que esta aproximação gera uma interação de aprendizado para os envolvidos, investigador e investigado, benéfica não só para o conhecimento científico como para a comunidade-alvo do estudo.

Para o epidemiologista formado dentro da concepção de análise de dados pelo método quantitativo, o manuseio de informações de carácter qualitativo, de natureza fatual ou opinativa, apresenta dificuldades, contornáveis na medida que buscar apoio em profissionais de outras áreas com vivência nesses estudos, e na me dida que, acreditando na riqueza de subsídios para o raciocínio epidemiológico que o método proporciona, procurar adquirir experiência no mesmo.

The advantages and difficulties for the use of the case study method on epidemiology are discussed by the au thor.

\section{REFERENCIAS BIBLIOGRÄFICAS}

1. ANDER-EGG, E - Inooduccion a las tecnicas de investigacion social. Buenos Aires, Ed. Humanitas, 1969. p. 132-133.

2. BOYD, JR., H. \& HARPER, W. - Pesquisa mercadológica Textos e casos Rio de Janeiro, Fundação Ge túlio Vargas, 1964, vol. 1, p. 59-63.

3. BRANDÃO, C.R. - Repensando a pesquisa participante. São Paulo, Brasiliense, 2 a ed., 1985, p. 7.

4. CARTWRIGHT, A. - Health survey's in practice and in poten. cial; a critical review of their scope and methods. London, Hollen Street Press, 1983, p. 162.

5. FERNANDFS, F. - Ensaios de Sociologia geral e aplicada. São Paulo, Pioneira 1960, p. 251-69.

6. IVERSSON, L. B. - Aspectos da epidemia de encefatite por Cadernos de Saúde Pública, RJ., 3 (1):16-21, jan/fev, 1987 
arbovirus na região do Vale do Ribeira, São Paulo, Brasil, no período de 1975 a 1978. Rev. Saúde priblica, S. Paulo, 14: 9.35, 1980 .

7. MALINOWSKI, B. - Os argonau tas do mundo ociden tal. São Paulo. Ed. Abril, 1976.

8. MANN, P. H. - Métodos de investigaçăo sociológica. Rio de Janeiro, Zahar 1979, p. 121-3.

9. SELLTIZ, C.; JAHODA, M.; DEUTSCH, MB \& COOK, S.W. Métodos de pesquisa nas relações sociais. São Paulo, HerderEDUSP, 1967 , p. 59-60,

10. SPINOLA, A. W. - Métodos e técnicas de pesquisa: Uma nota sobre o estudo de caso e a observação. SERVIR, 19 (4): $175-7,1981$. 